\title{
Advances in intraocular techniques in the treatment of retinal detachments arising from holes of the posterior pole*
}

\author{
S. BINDER AND B. RISS
}

From the First University Eye Clinic, Vienna

SUMmARY Two groups of retinal detachments arising from macular holes were compared. The first group consisted of 27 consecutive cases operated upon during the years 1972-7 by various techniques (encircling and hemi-encircling procedures, scleral resection, scleral pocket, and silver clip). The second group consisted of 18 consecutive cases operated upon in the years 1978-81 by pars plana vitrectomy to release vitreous traction or make intraocular manoeuvres possible. In all cases of the second group an intraocular gas bubble was used to tamponade the macular hole, and the hole was coagulated only if necessary. There was not only a significantly better anatomical result in the second group, but the functional results were more favourable. Two-thirds of the eyes of the second group reached a visual acuity between $6 / 12$ and $6 / 48$, while in the first group none of the eyes gained a better vision than $6 / 60$. The reading vision in $2 / 3$ of the first group was negligible, while nearly half of the cases in the second group reached useful acuity between Jaeger 3 and 10.

Until recently the only aim in surgical treatment of retinal detachments arising from macular holes was anatomical reattachment; functional results were a secondary consideration. Many methods have been proposed for the treatment of such detachments, including encircling and hemi-encircling procedures, ${ }^{12}$ special techniques of episcleral buckling of the posterior pole, either with plombs, ${ }^{3-5}$ a scleral pocket,${ }^{67}$ or a silver clip. ${ }^{8-11}$ The disadvantages of these methods include difficult manipulation due to the location of the hole, possible trauma to the short ciliary vessels and the optic nerve, and a high risk of haemorrhage from the drainage of subretinal fluid.

The introduction of vitreous surgery by Robert Machemer ${ }^{12}$ led to (1) release of vitreoretinal traction; (2) creation of a fluid space within the vitreous cavity from which fluid can be removed to create a scleral buckle and/or introduce an intravitreal bubble; (3) techniques for transvitreal drainage; and (4) transvitreal treatment.

It is the purpose of this study, to ascertain if the use of such intraocular techniques improved anatomical or functional results.

Correspondence to Dr S. Binder, 1 Augenklinik der Universität Wien, Spitalgasse 2, 1097 Vienna, Austria.

*Presented at XIII Meeting of the Club Jules Gonin in Conolobe. March 1982.

\section{Material and methods}

A total of 45 consecutive cases with retinal detachment and macular holes were treated surgically from 1972 to 1980 at the First Eye Clinic of Vienna. This number comprised 12 males and 33 females, with an average age of 63 years. In 24 cases the right eye and in 21 cases the left eye was involved. We compared 2 groups. The first group consisted of 27 cases $(=27$ eyes) which were operated upon during the years 1972 to 1977 by different surgeons, and the second group consisted of 18 cases ( $=18$ eyes) which were operated upon between 1978 and 1981. The causes of the macular holes are shown in Table 1 . Twenty-six eyes had myopia higher than $8 \mathrm{D}, 3$ cases suffered ocular trauma, 3 cases had previous cataract operation, and 2 eyes retinal reattachment operation; in one eye the macular hole arose after a branch vein occlusion, and 9 eyes had small refraction errors in elderly patients ( 65 years or older).

The various techniques used in the first group included (Table 2) encircling or hemi-encircling procedures in 4 cases, temporal scleral resection in 4 cases; local plombs were applied in 6 cases, a scleral pocket was fashioned in 2 cases, in one eye an encircling procedure was combined with a posterior plomb; only diathermy and drainage of the fluid was 
Table 1 Reasons for macular holes and detachment

\begin{tabular}{|c|c|c|c|c|c|c|c|}
\hline & \multirow[t]{2}{*}{ Myopia $8 D$} & \multirow[t]{2}{*}{ Trauma } & \multirow{2}{*}{$\begin{array}{l}\text { Aphakia+ } \\
\text { myopia }\end{array}$} & \multicolumn{2}{|c|}{ Operation } & \multirow{2}{*}{$\begin{array}{l}\text { Ven. } \\
\text { occl. }\end{array}$} & \multirow[t]{2}{*}{ ?Senile } \\
\hline & & & & Cat. & Ret.det. & & \\
\hline Group I & 19 & 1 & 1 & 1 & - & - & 5 \\
\hline Group II & 7 & 2 & - & 2 & 2 & 1 & 4 \\
\hline Total & 26 & 3 & 1 & 3 & 2 & 1 & 9 \\
\hline
\end{tabular}

Cat.$=$ cataract. Ret. det.$=$ retinal detachment. Ven.occl. $=$ venous occlusion.

done in 3 cases, and in 7 cases a silver clip operation was performed. In all cases some sort of coagulation of the macular hole was done including diathermy, cryo- or photocoagulation. Sometimes several treatments of different kinds of coagulation in the same eye were necessary.

The techniques used in the second group (Table 3 ) included a pars plana-vitrectomy with the Ocutome in 11 cases, in which either vitreous traction was obvious or the creation of a free space for an intravitreal gas bubble or transvitreal manoeuvre was needed. In cases of retinal detachments where peripheral breaks existed ${ }^{7}$ vitrectomy was not done, but the peripheral holes were treated with a cryotherapy and buckle operation, subretinal fluid was drained transsclerally, and the primary macular hole was left without coagulation but tamponated with an intraocular gas bubble. We used a combination of SF 6 and air in a proportion of $20: 80 \%$. In 12 cases additional laser treatment was needed after the operation, in 5 cases because the intraoperative cryotherapy seemed to be insufficient and in 7 cases because the primary uncoagulated hole started to show a small rim of subretinal fluid. However, in 3 cases the uncoagulated macular hole healed spontaneously, making further laser treatment unnecessary.

Table 2 Various operative techniques used to treat retinal detachments with macular holes during 1972-7 (group I)

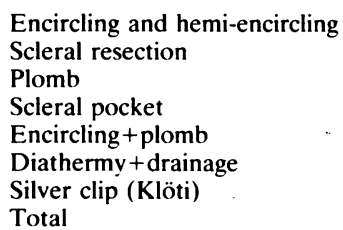

Table 3 Intraocular techniques used to treat retinal detachment arising from macular holes during 1978-81 (group II)

Vitrectomy + intraocular cryo or ext. cryo intraocular drainage, intraocular gas

Encircling or plomb, ext. drainage, intraocular gas Total

\section{Results}

In the 27 cases which were operated upon between 1972 and 1977 (group 1) the retinal detachment was replaced in 16 eyes and remained detached in 11 . In the 18 cases which were operated upon between 1978 and 1980 in 17 retinas were reattached and one retina remained detached. The difference in results in the 2 groups is statistically significant $(p<0.05)$ in favour of the second group.

Comparison of the functional results in the cured cases from both groups (17 and 16) (Table 4) shows that one-third of the eyes from the second group reached a visual acuity between $6 / 12$ and $6 / 48$, while in the first group none of the eyes gained a better vision than $6 / 60$. As regards near vision, no reading vision was reached in more than two-thirds of group 1 , while half of the cases of the second group maintained useful reading vision between Jaeger 2 and 10.

\section{Discussion}

In considering the 2 groups some points should be borne in mind. (1) Two-thirds of the cases in group 1 were high myopes, while in group 2 less than half of the eyes were myopic and the remainder had causes with an expectation of a more favourable prognosis. (2) There was an unexpected cure in one case of the second group several months after the detachment

Table 4 Functional results of the cured cases with retinal detachments arising from macular holes

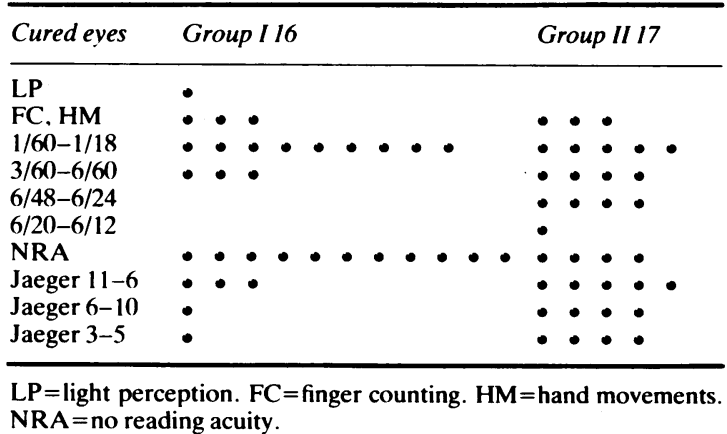


operation. It was a highly myopic eye, where in spite of vitrectomy, cryocoagulation, intraocular tamponade, and laser treatment the retina remained detached in the inferior half. After 6 months the macular hole healed spontaneously due to preretinal membrane formation and the retina reattached.

It is concluded that vitreous surgery has more to offer in the treatment of detached retinae due to the formation of macular holes than the standard methods involving scleral indentation.

\section{References}

1 Oliver GL. Retinal detachments caused by macular and perimacular breaks. Can J Ophthalmol 1969; 4: 24-6.

2 Liesenhoff $H$. Die vertikale Halbcerclage, eine neue Methode zur Operation desperater Netzhautablösungen mit Makulaforamen. Buech Augenarzt 1970; 53: 70-5.

3 Pannarale MR. Rilieri sui distacchi retinici con foro maculare. Osservazione su 145 casi. Boll Oculist 1957; 46: 733-58.
4 Hager G. Die T-Plomben-Plastik, eine neue Ablatio-Operation Klin Monatsbl Augenheilkd 1968; 153: 624-5.

5 Margherio RU, Schepens CL. Macular breaks. 2: Management. Am J Ophthalmol 1972; 74: 233-40.

6 Bonnet M. Behandlung der durch makulare oder paramakulare Risse entstandenen Netzhautablösungen durch die Skleratasche. Klin Monatsbl Augenheilkd 1971; 158: 1-7.

7 Paufique L, Bonnet $\mathrm{M}$. Traitement du décollement de la retine avec déchirure vraie de la macula par la technique de la poche sclérale. Ann Oculist (Paris) 1968; 201: 290-302.

8 Klöti R. Eine Operationsmethode für makulalochbedingte Netzhautabhebungen. Ophthalmologica 1964; 148: 42-56.

9 Klöti R. Eine Operationsmethode mit Silberklemme bei makulalochbedingter Amotio. Mod Probl Ophthalmol 1966; 4: 246-52.

$10 \mathrm{Klöti}$ R. Erfahrungen mit der Silberklemme bei makulalochbedingten Netzhautablösungen. Ophthalmologica $1970 ; 161: 210-6$.

11 Klöti R. Silverclip for central retinal detachments with macular hole. Mod Probl Ophthalmol 1974; 12: 330-6.

12 Machemer R. Vitrectomy-a pars plana approach. New York: Grune and Stratton, 1977. 